\title{
The Main Causes of Calf Mortality in Dairy Farms in
}

\section{Poland}

\author{
Justyna Żychlińska-Buczek ${ }^{1}$, Edyta Bauer ${ }^{2}$, Joanna Kania-Gierdziewicz ${ }^{2}$ and Anna Wrońska ${ }^{1}$ \\ 1. Department of Cattle Breeding, University of Agriculture in Krakow, Krakow 30-059, Poland \\ 2. Department of Genetics and Animal Breeding, University of Agriculture in Krakow, Krakow 30-059, Poland
}

\begin{abstract}
Calf mortality is one of important problems of calf rearing in dairy farms worldwide. Besides, several noninfectious factors, such as management around birth, colostrum management, calf housing, feeding system, hygiene and pathogens, play an important role in calf rearing. The aim of the study was to show the most common causes of mortality of calves up to $90 \mathrm{~d}$ of their lives. Some data are available concering calf rearing management on small and medium size dairy farm typical for Polish regions. The research was conducted in seven selected herds of Polish Holstein-Friesian cows located in South of Poland. Data on calves mortality covered the period of three years from 2004 to 2007 and were collected using medical documentation and medical inquire in the farms. All evidence was enrolled untill three months of age of calves. There were 1,800 calves tested. The influence of such factors as maintaining system (free stalls barn and stalls barns), feeding systems and herd size on falls of calves was examined. Overall, mortality throughout the three months of study period was diarrhea, which increased the risk of death among calves younger than $90 \mathrm{~d}$ of age. Also, respiratory system disorders were the common cause of loss of calves. The calf mortality rate during $90 \mathrm{~d}$ in all herds registered in free stall barns was $61 \%$ and in stalls barns was only $29 \%$. Effect of pneumonia in free stall barns was $18 \%$ and in stall barns was $29 \%$. In all groups, calf mortality rates increased with increasing herd size.
\end{abstract}

Key words: Dairy cattle, calf health, calf mortality.

\section{Introduction}

Healthy calves form the basis of any successful cattle production system, from both economic and animal welfare points. The most common health problem is diarrhea in newborn calves, which causes great economic loss to dairy producers [1]. Diarrhea is a complicated, multifactoral disease with noninfectious factors and numerous infections. In breeding of dairy cattle very important is proper rearing of calves. Healthy, well-reared calf ensures the breeding progress in milk production. Also, movement and condition of cows are the factors that support calving. Calves which are intended for replacement in the herd should be characterized by good health.

The focus on disease prevention rather than veterinary treatment means that an efficient health

Corresponding author: Edyta Bauer, Ph.D. student, research fields: animal genetics and breeding. supervisory system is necessary.

Assessment of animal welfare requires development of new strategy based on information obtained by many measurements. Welfare measurements may differ in accuracy, relevance and relative importance for overall well-being. Because of an increasing interest in assessment of calf welfare, it is necessary to collect data that can supply information about the quality and animal-friendly way of animal housing and care [2]. To determine the influence of different systems of keeping healthy calves on welfare, it is necessary to prepare one system with welfare standards that could be used under various conditions. The aim of the study was to evaluate and compare welfare of calves on selected dairy farms. Proper care of the calves during feeding of colostrum could protect animals from health problems later in life. Unfortunately, despite of the best intentions and well done work, calves are not always protected against 
diseases [3, 4]. Most common health problems of calves could be divided into a couple of groups depending on easily calving. The first group contains cases of stillborn calves with weak calf syndrome and birth defects, the second group contains cases of diarrhea and the last group contains the latest occurring respiratory diseases. However, many of these factors are not modifiable on commercial dairy farms.

What should also be mentioned is the possibility of the birth of weak or deformed calves by the administration of certain drugs during pregnancy of the cows [5]. Most often this occurs because of lack of knowledge and uncontrolled usage of drugs without consultation or supervision of a veterinarian, who should be the most competent person in such cases. Some drugs result in developmental defects or fetal death. The most common birth defects in of calves include lung atelectasis, changes in the brain, no anus and same others. Also, what should be important to remember is the genetic base of these changes that may occur through inattentive matching bulls for artificial insemination or coverage of closely related animals [6].

\section{Materials and Methods}

The study was designed as a case-control study and the dependent variable in all statistical models was the type of farm.

Data consisted of information gathered over three years (2004-2007) period in a production environment. Data on falls of calves were analyzed on the basis of medical documentation and medical history in individual farms on the material counting a total of 1,800 pieces of cows Polish black and white Holstein-Friesian. Cows involved in tests were used in seven farms located in the provinces of South Poland.

To achieve good similarity in structure, the type of farm, the type of cow barn (free barn stall or stalls barns) and the number of dairy cows were used as further criteria. Suitable farms were available in the same geographical region. A questionnaire was used to collect information during a face-to-face interview with the farm owner or manager. Space of interest were farm characteristics, health status of animals, calf housing and feeding, focus on calves within the 90 days of life, management practices around calving and birth, as well as hygienic measures. The percentage of contaminated places was documented (0 to $100 \%$ ).

Respiratory tract disease was defined as several increased respiratory sounds at lung auscultation or as moderately increased respiratory sounds together with additional signs, such as dyspnea, coughing or nasal discharge.

On all farms, calves were usually separated within $24 \mathrm{~h}$ after birth. On almost all farms, the attendants or manager stated that each calf received colostrum within $6 \mathrm{~h}$ after birth or some were allowed to suckle their dam.

On the bigger farms, calves were housed individually after birth, usually for 1-12 weeks, with a median of six weeks. Calves were grouped after weaning. All calves were housed on long straw during pre-weaning period. Individual housing was cleaned daily or farmer indicated that fresh straw was added if necessary, and pens were cleaned after the calf left the box.

On most of the farms, milk or milk replacer was fed restricted to $10 \%$ to $12 \%$ of the calf body weight (BW), usually in two meals per day. On none of the farms was found the amount of solid food eaten by the calf before weaning. Hay was offered to the calves from the second week of the life. On the bigger size farms, calves had free access to concentrates, starting within the first three weeks of life.

The calves were categorized as clean or mildly dirty in all farms. The calving area was cleaned after each calving in every farm.

\section{Characteristics of Evaluated Farms}

\subsection{The Family Farm (A)-Polish Black and White Holstein-Friesian Cattle}

The free barn stall maintenance system with deep 
litter concerns 55 dairy cattle with an average yield of $7,500 \mathrm{~kg}$ of milk per lactation. Milking takes place in the parlor of "herringbone stall". There is no grouping nutritional feed station. Age of first calving on farm A is $\geq 24$ months. The length period is between $275 \mathrm{~d}$ and $302 \mathrm{~d}$.

\subsection{The Family Farm (B)_Polish Black and White Holstein-Friesian Cattle}

Positions of system maintenance were long straw and manual feed. There are 24 cattle with an average yield 5,500 kg of milk per lactation. Milking is done using pipeline milking machine.

\subsection{State Farm (C)-Polish Black and White Holstein-Friesian Cattle}

Positions of system maintenance were long straw and manual feed inflicted by hand. There are 40 cattle with an average yield $6,500 \mathrm{~kg}$ of milk per lactation. Milking is done using pipeline milking machine. Calving at $\geq 22$ months was practice on farm $\mathrm{B}$. The length period was between $277 \mathrm{~d}$ and $298 \mathrm{~d}$.

3.4 The Family Farm (D)_Polish Black and White Holstein-Friesian Cattle Varieties of $75 \%$ Share of Holstein-Friesian Genes Race

The maintenance system in the free barn was deep bedding, while the nutrition system was a mixed feeding. There were 60 cattle with an average yield $6,500 \mathrm{~kg}$ of milk per yield. Milking takes place in the parlor of "herringbone stall". Age at first calving is between 23 months and 24 months. The length period is between $270 \mathrm{~d}$ and $295 \mathrm{~d}$.

\subsection{The Family Farm (E)_Polish Black and White Holstein-Friesian Cattle}

The free barn stall maintenance system was deep bedding, while the nutrition system was a mixed feeding. There were 259 cattle with an average yield of $6,500 \mathrm{~kg}$ milk per lactation. Milking takes place in the parlor of "herringbone stall". Calving is at age $\geq$
23 months. The length period is $<272 \mathrm{~d}$ and $>273 \mathrm{~d}$.

3.6 The Family Farm (F)-Polish Black and White Holstein-Friesian Cattle Varieties of 75\% Share of Holstein-Friesian Genes Race

The free barn stall maintenance system was deep litter bedding system, while the nutrition system was a mixed feeding. The number of 250 cattle with an average yield 7,500 $\mathrm{kg}$ of milk per lactation. Milking takes place in the parlor of "herringbone stall". Calving period is between 22 months and 24 months. The length period is $\geq 280 \mathrm{~d}$.

\subsection{The Family Farm (G)_Polish Black and White} Holstein-Friesian Cattle Varieties of $75 \%$ Share of Holstein-Friesian Genes Race

The free barn stall maintenance system was deep litter bedding system, while the nutrition system was a mixed feeding. The number of 104 cattle with an average yield $8,500 \mathrm{~kg}$ of milk per lactation. Milking takes place in the parlor of "herringbone stall". First calving is at age $\geq 22$ months. The length period is $\geq$ $278 \mathrm{~d}$.

The work is based on interviews carried out with environmental survey and based on the documentation breeding, i.e., card heifer-cow farms located in South of Poland. Intention of the interview was to establish the most common causes of calves' mortality up to 90 $\mathrm{d}$ of age.

\section{Results}

The results concerning the impact of such various factors as how to maintain free barn system or tie-stall system, farm size, breed and causes of falls of calves are shown graphically in Figs. 1 and 2 and Tables 1-5. Fig. 1 presents the result of calving during year of 2004 depending on maintenance system, like tie-stall and free barn system. The year has been divided into seasons.

The collected data show that in farms with free barns system, distribution of calving during the year 


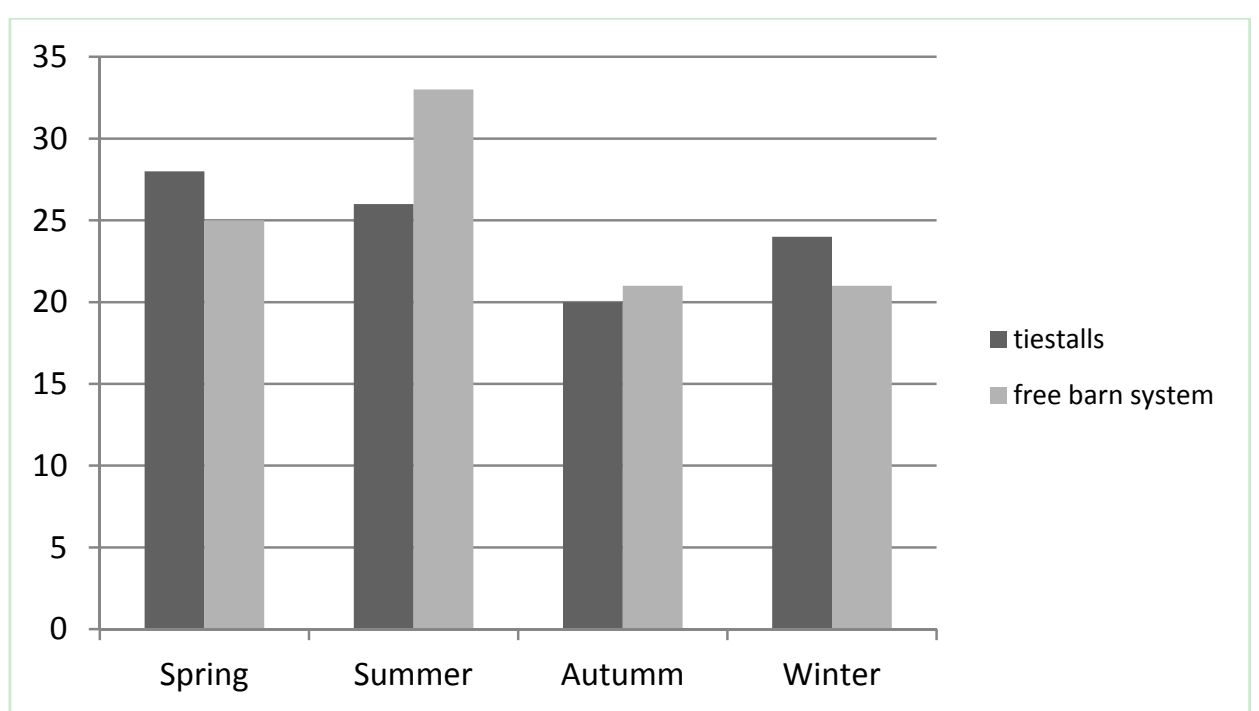

Fig. 1 The distribution of calving in the year of 2004 depending on system maintenance.

Table 1 Causes of calves mortality in free barn housing system.

\begin{tabular}{ll}
\hline Free barns housing & Percentage \\
\hline Diarrhea & $61 \%$ \\
Postnatal respiratory disorders & $18 \%$ \\
Perinatal & $14 \%$ \\
Malformations & $3 \%$ \\
\hline
\end{tabular}

Table 2 Causes of falls of calves in tie-stall system.

\begin{tabular}{ll}
\hline Barns housing & Percentage \\
\hline Diarrhea & $29 \%$ \\
Postnatal respiratory disorders & $29 \%$ \\
Perinatal & $28 \%$ \\
Malformations & $14 \%$ \\
\hline
\end{tabular}

Table 3 Causes of calves mortality on the farm A (50-100 pieces).

\begin{tabular}{ll}
\hline Barns housing & Percentage \\
\hline Diarrhea & $46 \%$ \\
Postnatal respiratory disorders & $38 \%$ \\
Perinatal & $8 \%$ \\
Malformations & $4 \%$ \\
Others & $4 \%$ \\
\hline
\end{tabular}

Table 4 Causes of calves mortality on farm B (101-200 pieces).

\begin{tabular}{ll}
\hline Barns housing & Percentage \\
\hline Diarrhea & $33 \%$ \\
Perinatal & $20 \%$ \\
Postnatal respiratory disorders & $27 \%$ \\
Malformations & $20 \%$ \\
\hline
\end{tabular}

was the highest number in the period of calving years $(33 \%)$, while in the holdings of the tie-stall system, calving season is distributed relatively equally throughout the years (Fig. 1).
Table 5 Causes of calves mortality on the farm C (201-300 pieces).

\begin{tabular}{ll}
\hline Barns housing & Percentage \\
\hline Diarrhea & $69 \%$ \\
Perinatal & $10 \%$ \\
Postnatal respiratory disorders & $8 \%$ \\
Malformations & $8 \%$ \\
Others & $5 \%$ \\
\hline
\end{tabular}

Based on the interpretation of the results, it was found that in the tie-stall maintain system, calves mortality are caused by diarrhea and postnatal respiratory disorder $(29 \%)$ and no proper proceedings of the calf after delivery, which is at the level $28 \%$ (Table 2).

The impact of the number of cows on the distribution of calving on the farm $\mathrm{A}$ was the highest in the summer months (44\%) and the lowest in the fall and winter range (14\%-16\%).

On farms $\mathrm{B}$ and $\mathrm{C}$, the difference between the distribution of was slightly more visible in farm $\mathrm{C}$. This difference is $10 \%$ in favor of farm $\mathrm{C}$. These differences are shown in Fig. 2.

Considering size of farms, number of cows and calves in a farm, the cause of mortality of calves in these farms was diarrhea (farm A: 46\%; farm B: 33\%; farm C: $69 \%$ ).

The data given in Tables 3-5 show that the causes of mortality in these farms are as follows: postnatal respiratory disorders in farm $\mathrm{A}$ are $38 \%$, in farm $\mathrm{B}$ are 


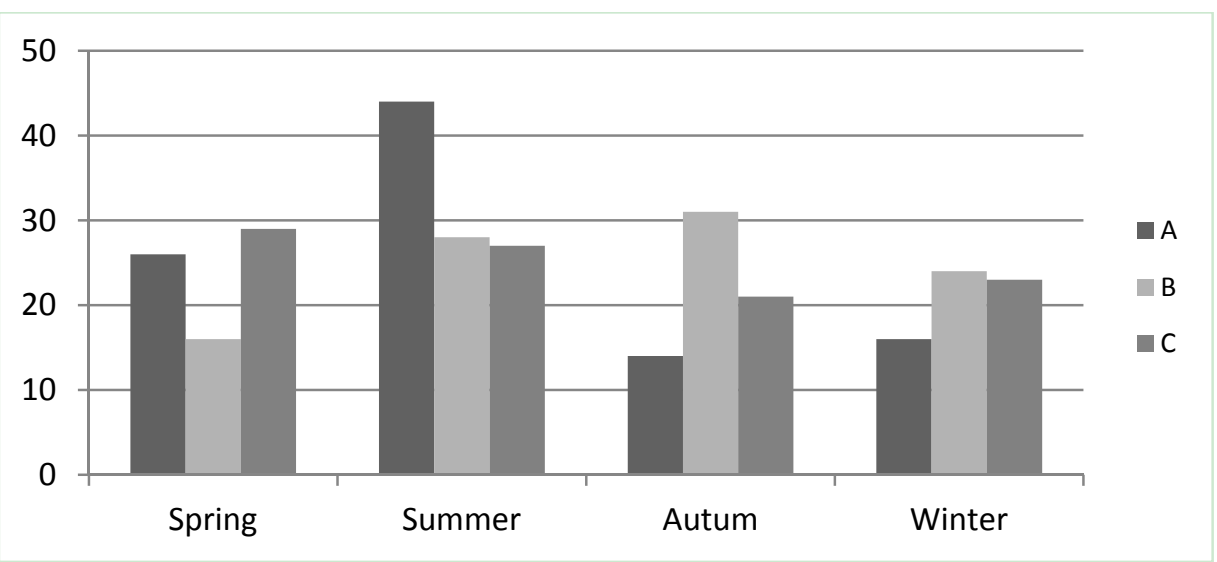

Fig. 2 The distribution of calving in 2004 depending on the size of farms (\%).

Classification of households depended on the number of cows. A: 50-100 pieces; B: 101-200 pieces; C: 201-300 pieces.

$27 \%$ and in farm $\mathrm{C}$ are $8 \%$; the proceedings of calf after birth in farm $\mathrm{A}$ are $8 \%$, in farm B are $20 \%$ and in farm $\mathrm{C}$ are $10 \%$, Malformation cases on farm A are noted $4 \%$, in farm $\mathrm{B}$ are $20 \%$ and in farm C are $8 \%$.

In addition, in the farm $\mathrm{A}$ and $\mathrm{C}$, some live-born calves with a genetic defect called molformations were recorded, which causes death soon after birth. Percentage of mortality in both farms was $5 \%$ (Tables 3 and 5).

In the farm $\mathrm{C}$, the largest mortality of cows calving was recorded to be caused by diarrhea (Table 5).

\section{Discussion}

This study surveyed and described management practices in calf rearing on dairy farms in Polish free land to identify risk factors of calf's mortality on those farms. Except for farm characteristics, the type of the cow facilities, breed and caretaker were similar among farms. In this study, the presence of diarrhea was significantly associated with herd size. Similar results concerning the association between the appearance of diarrhea and herd size were obtained in Ref. [7]. Another factor that might influence the risk for diarrhea is the time which the calf spends with a mother in the calving area. Especially, poor hygiene condition was not a risk factor on the examined farms. The importance of an adequate colostrum supply and therefore the passive transfer of immunoglobulins for calf health is well known. In the first week of age, calves are commonly advised to be housed individually, because it may lead to a decreased pathogen load [8]. Moreover, grouping relatively late in the calves' life (median of six weeks with interquartile range 4-8 weeks) could have positively influenced morbidity, because the risk for diarrhea is the highest in the first three weeks of their life [9]. On all farms which have been visited, calfs were fed with whole milk. Additional advantages of feeding whole milk are easier and less error-prone than feeding milk replacer. The farms had similarity feeding management system. Based on the research, it can be concluded that the most common cause of mortality of live-born calves was diarrhea. Similar conclusions were reached in Refs. $[3,4,10]$, in which it was also reported that because of diarrhea, especially in the first period of life of calves, the mortality was observed. This is also confirmed in Ref. [5] that the steady intensification of livestock farming leads to a high concentration of animals in a small area. This phenomenon favors the spread of infectious diseases, particularly in calves. Currently, $80 \%$ of cases of disease in this age group are disorders of a diarrhea and respiratory syndrome, which was also demonstrated in this work. Similar values were received in Ref. [11], which confirmed that diarrhea and respiratory diseases accounted for approximately $80 \%$ of cases of disease in calves and were the main 
cause of business failure and economic losses. In this study, the presence of respiratory tract disease was significantly associated with diarrhea. Furthermore, the number of farms with calves suffering from respiratory tract disease was lower.

Stefaniak [12] argued that the period of neonatal diarrhea was one of the main reasons of morbidity and mortality of calves. It is estimated that the period of acute diarrhea causing $75 \%$ calf deaths was three weeks. Especially, dangerous for calves is infectious diarrhea. They are most commonly caused by enterotoxigenic strains of Escherichia coli and Rotavirus, with which particularly dangerous infections are mixed. If the calf is affected with diarrhea, it significantly increases the risk of other diseases, especially respiratory organ infection.

Sobiech [11] has distinguished three periods of the incidence of diarrhea: postnatal (1-4 d), weaned and the transition to a newborn calf period. Normally, illness lasted about a week, and the recovery period was 3-5 d. The reasons are the following: dietetic, bacterial, fungal, viral, toxic, parasitic, allergic and stressful.

A major health problem in the case of diarrhea of calves as well as in other animals is the dehydration caused by increased loss of fluids in the body and reduction of their delivery with milk. Long-term and persistent diarrhea can lead to disorders of homeostasis with fatal outcome [13].

According to some opinions of Stefaniak [12], quite important but often underestimated, the cause of the diarrhea may be the shortage of calcium in milk, which extends time of clotting of casein in the abomasum and threatens emergence of a "full stomach diarrhea". Regardless of the cause, primary intestinal dysfunction is conducive to connect with the infectious agents, risk of diarrhea is directly proportional to the concentration of pathogens in the environment, which depends on how are the wagon, cleaning and disinfecting stalls, air quality, walls and other environmental factors.
According to Refs. [14, 15], respiratory diseases affect over $90 \%$ of the calves, the percentage of dead relative to their total number is $5.3 \%$, and the percentage of deficiency reaches $4.5 \%$. Respiratory diseases of calves, known as "the flu calves" or enzootic bronchopneumonia (EBPC), are the main economic problem in rearing calves in both herds of cattle milk and meat production profile.

The cause of influenza calves is complex collaboration of environmental factors and microorganisms. Among the factors, stress factors are non-communicable, but they play an important role, in such as a transport, a dietary mistakes, a change of environment, a method of animal care, a microclimate of premises and veterinary treatments [14].

The problem with bovine viral diarrhea (BVD) in a herd usually occurs as a result of purchase of new animals that are infected temporarily or permanently. Chance of being infected can result from contact with animals on pasture in the neighborhood or wild ruminants and during maintenance [2].

The main problem in controlling BHV-1 infection is the presence of the virus after infection in ganglia and peripheral nerve fibers throughout life of the animal host. Re-virus excretion may take place almost always after activation of stress factors (e.g., parturition). Other illnesses and the use of glucocorticoids also run shoemaking. Therefore, each animal is seropositive to the sower of the potential of the virus [2].

Proper breeding developments affect not only the growth of animals and their health, but also for the development of organs, which in productive age can decide later use value of youth destined for the renewal of the dairy herd, as well as cost rearing and use of milk. Especially, the important is the period of feeding the liquid with feed when calves are not yet fully developed rumen and the enzymatic activity the digestive tract is limited. The improper nutrition and keeping calves during this period make respiratory and digestive tract worse, consequently leading to a 
reduction in their subsequent productivity of milk [16].

Rearing of healthy and well-developed calves intended to reproduce the dairy herd depends on efficiency of cattle breeding and use [17]. Mistakes in nutrition, lack of maintenance and increased concentration of calves lead to increased stress and the lower immunity. The results of incorrect rearing are substantial financial losses due to mortality of animals and the weak and sick heifers, which in the future will be difficult to calve and will produce small amounts of milk of low quality [6].

Stefaniak [12] and Sobiech [13] found that we can prevent the occurrence of diseases neonatal period by proper handling of the calf after birth, caring for quick and correct colostrums-drinking calves, taking care of the hygiene of the environment in which calves are born and reside, disinfection of premises and mulch as well as specific active immunization of pregnant cows.

\section{Conclusions}

Many calf rearing management factors were similar between the visited farms, while variables significantly related to diarrhea on the farm were farm size.

The most common cause of calve mortality before reaching $90 \mathrm{~d}$ of age is diarrhea. The second most common cause of calve losses is respiratorypostnatal respiratory disorders and digestive systemcatarrhal enteritis. It is concluded that different housing system in dairy farming can be a problem during 1-90 $\mathrm{d}$ on coexisting issues concerning calf management and health. When dealing with calf mortality problems, it can be helpful to bear in mind of these coexisting issues and include analyses of the entire herd situation.

Bovine perinatal mortality is increasingly being viewed as a dairy cattle welfare problem.

\section{References}

[1] Torsein, M., Lindberg, A., Sandgren. C. H., Waller, K. P., Tornquist, M., and Svensson, C. 2011. "Risk Factors for Calf Mortality in Large Swedish Dairy Herds." Prev. Vet. Med. 99: 136-47.

[2] Blokhuis, H. J., Jones, R. B., Veissier, I., and Geers, R. 2006. Measuring and Monitoring Farm Animal Welfare. Leuven, Belgium: K.U. Leuven R\&D, 48.

[3] Niwińska, B. 2010. "Causes of Falls of Calves." Cattleman 10: 20-6. (in Polish)

[4] Nogalski, Z. 2009. "The Mortality Rate of Calves during the First Days of Life." Cattleman 9: 20-7. (in Polish)

[5] Bednarski, M., and Wieliczko, A. 2009. "Infectious Diseases of Calves-Diagnostic Capabilities." In Proceedings of the Infant and the Environment-Deficiencies in Calves and Cows Conference, 45-51. (in Polish)

[6] Rozwadowska, M., and Nowaczyk, A. 2008. "From Cattle to the Cow." P. J. Cattle 1: 14-6. (in Polish).

[7] Vaarst, M., and Sørensen, J. T. 2009. "Danish Dairy Farms' Perceptions and Attitudes Related to Calf-Management in Situations of High Versus No Calf Mortality." Prev. Vet. Med. 89 (1-2): 128-33.

[8] Barrington, G. M., Gay, J. M., and Evermann, J. F. 2002. "Biosecurity for Neonatal Gastrointestinal Diseases." Vet. Clin. North Am. Food Anim. Pract. 18 (1): 7-34.

[9] Svensson, C., and Liberg, P. 2006. "The Effect of Group Size on Health and Growth Rate of Swedish Dairy Calves Housed in Pens with Automatic Milk-Feeders." Prev. Vet. Med. 73 (1): 43-53.

[10] Chmielnik, H., and Sawa, A. 1998. "The Causes of Perinatal Mortality of Calves." Problematic Notebooks of Progress in Agricultural Sciences 333: 135-9. (in Polish)

[11] Sobiech, P. 2006. "Diarrhea in Calves." P. J. Cattle 12: 66-7. (in Polish)

[12] Stefaniak, T. 2004. "Diarrhea is the Enemy No. 1." Breed with the Head 6: 31-41. (in Polish)

[13] Sobiech, P. 2007. "Diarrhea in Calves." P. J. Cattle 1: 67-8. (in Polish)

[14] Rypuła, K., and Karczmarczyk, R. 2005. "Calves Flu." P. J. Cattle 3: 42-5. (in Polish)

[15] Rypuła, K., Karczmarczyk, R., and Płoneczka, K. 2007. "Respiratory Diseases in Calves." Breed with the Head 5: 57-61. (in Polish)

[16] Bilik, K. 2006. "Immunity from the Bucket." Breed with the Head 1: 30-1. (in Polish)

[17] Niwińska, B., and Bilik, K. 2008. "How to Cover the Needs of Minerals for Calves?" Breed with the Head 7: 44-6. (in Polish) 